Word counts: 4499 words for the text and 232 words for the abstract

2

3 Title: Personal exposure to fine particulate matter, lung function and serum club cell

4 secretory protein (Clara)

5 Running head: $\mathrm{PM}_{2.5}$, lung function and $\mathrm{CC} 16$

6

7 Authors' full name: Cuicui Wang, ${ }^{\text {a† }}$ Jing Cai, ${ }^{\text {a† }}$ Renjie Chen,,${ }^{a}$ b Jingjin Shi, ${ }^{\text {a }}$ Changyuan

8 Yang, ${ }^{a}$ Huichu Li, ${ }^{a}$ Zhijing Lin, ${ }^{a}$ Xia Meng, ${ }^{a}$ Cong Liu, ${ }^{a}$ Yue Niu, ${ }^{a}$ Yongjie Xia, ${ }^{a}$ Zhuohui

9 Zhao, ${ }^{a}$ Haidong Kan ${ }^{a, b, *}$

$10{ }^{\dagger}$ Co-first authors that contributed equally to this work

12 Affiliations: ${ }^{a}$ School of Public Health, Key Lab of Public Health Safety of the Ministry of

13 Education and Key Lab of Health Technology Assessment of the Ministry of Health,

14 Fudan University, Shanghai 200032, China;

15 bShanghai Key Laboratory of Atmospheric Particle Pollution and Prevention (LAP ${ }^{3}$ ),

16 Fudan University, Shanghai 20032, China

$17{ }^{*}$ Corresponding author

19 Address Correspondence to: Haidong Kan, Department of Environmental Health,

20 School of Public Health, Fudan University, P.O. Box 249, 130 Dong-An Road, Shanghai

21 200032, China. Tel: +86 (21) 54237908. E-mail: haidongkan@gmail.com. 


\section{Abbreviation list}

$25 \mathrm{PM}_{2.5}=$ particulate matters with aerodynamic diameters less than $2.5 \mu \mathrm{m} ; \mathrm{SD}=$ 26 standard deviation; IQR = interquartile range; LBAB, lung blood-air barrier; $L M E=$ linear 27 mixed effect; $\mathrm{BMI}=$ body mass index; $\mathrm{CV}=$ coefficients of variation; $\mathrm{Cl}=$ confidence 28 interval; $\mathrm{FEV}_{1}=$ forced expiratory volume in $1 \mathrm{sec} ; \mathrm{FVC}=$ forced vital capacity; PEF = 29 peak expiratory flow; $\mathrm{FEF}_{25-75}=$ forced expiratory flow at $25-75 \%$ of the pulmonary 30 volume; $\mathrm{CC} 16=$ Clara cell protein; $\mathrm{LME}=$ linear mixed-effect. 
ABSTRACT (232 words)

32 Background: The underlying mechanisms about the association between ambient fine particulate matter $\left(\mathrm{PM}_{2.5}\right)$ and lung function were unclear yet. Few epidemiological studies have evaluated the potential mediating effects of serum club cell secretory protein (Clara) (CC16), a biomarker of pulmonary epithelium integrity.

Methods: We enrolled 36 healthy, nonsmoking college students for a panel study in Shanghai, China from December 17, 2014 to July 11, 2015. We measured personal and real-time exposure to $\mathrm{PM}_{2.5}$ for 72-hour preceding each of four rounds of health examinations, including lung function test and serum CC16 measurement. We used linear mixed-effect models to examine the health effects over various lag times. Furthermore, we analyzed the mediating effect of $\mathrm{CC} 16$ on this association.

Results: Average $\mathrm{PM}_{2.5}$ exposure ranged from 40 to $52 \mu \mathrm{g} / \mathrm{m}^{3}$ across different lag periods. $\mathrm{PM}_{2.5}$ exposure was negatively associated with lung function and positively associated with serum CC16 concentration. For instance, an interquartile range increase in $0-6 \mathrm{~h}$ average exposure to $\mathrm{PM}_{2.5}$ was significantly associated with a $1.11 \%$ [95\% confidence interval $(\mathrm{Cl}): 0.50,1.74]$ reduction in $1-\mathrm{sec}$ forced expiratory volume and a $4.14 \%(95 \% \mathrm{Cl}: 0.86,7.41)$ increase in serum CC16. Increased serum CC16 contributed $3.9 \% \sim 40.0 \%$ of the association between $\mathrm{PM}_{2.5}$ and impaired lung function.

Conclusions: Acute exposure to $\mathrm{PM}_{2.5}$ was associated with decreased lung function and increased circulating $\mathrm{CC} 16$, which may be an important mediator in the effects on lung function injury induced by $\mathrm{PM}_{2.5}$. 
53 Keywords: Personal exposure; fine particulate matter; lung function; Clara cell protein;

54 mediation effect 


\section{Text (4499 words)}

\section{Introduction}

Lung function is an objective measure of respiratory health. Airborne particulate matter with an aerodynamic diameter of $2.5 \mu \mathrm{m}$ or less $\left(\mathrm{PM}_{2.5}\right)$ can travel deeply into the respiratory tract and reach the lung. A substantial body of environmental epidemiological evidence has shown that ambient exposure to $\mathrm{PM}_{2.5}$, over the longterm (years) and short-term (hours to days), is associated with a range of adverse pulmonary events (Fuertes et al., 2015; Gauderman et al., 2004; Kariisa et al., 2015; Lee et al., 2007; Moshammer et al., 2006; Mu et al., 2014; Ni et al., 2016; Rice et al., 2016; Zhao et al., 2015). However, there are two major limitations on these studies. First, the subjects of most these studies are restricted to vulnerable populations, such as children (Moshammer et al., 2006; Rice et al., 2016), adolescents (Fuertes et al., 2015; Gauderman et al., 2004), elderly people (Lee et al., 2007), patients with pulmonary diseases, (i.e., chronic obstructive pulmonary disease) (Kariisa et al., 2015; Ni et al., 2016) or population with high occupational exposure (i.e., traffic policemen) (Zhao et al., 2015). However, studies focusing on young adults who are the major labor force are extremely limited. Second, most of these studies relied on outdoor fixed-site monitoring stations to assess the exposure levels of each participant, leading to considerable measurement errors. There is a dearth of studies exploring the effects of $\mathrm{PM}_{2.5}$ on lung function based on personal exposure monitoring (Trenga et al., 2006).

The underlying mechanism regarding impaired lung function by $\mathrm{PM}_{2.5}$ is unclear (Paulin and Hansel 2016). Altered integrity and/or increased permeability of the lung 
blood-air barrier (LBAB) were associated with pulmonary function injury (Brauner et al., 2009). Short-term exposure to air contaminants, i.e., ambient ozone and particles, can result in lung epithelium hyper-permeability (Broeckaert et al., 1999; Provost et al., 2014), which might lead to acute lung dysfunction. In considering biomarkers for evaluating the permeability and/or the cellular integrity of the pulmonary epithelium, club cell secretory protein (CC16), formerly known as Clara cell protein (Winckelmann and Noack., 2010), is a highly plausible candidate (Broeckaert et al., 2000a; Broeckaert and Bernard 2000). CC16 is a small protein secreted mainly by non-ciliated bronchiolar Clara cells in the respiratory epithelium of bronchioles (Lakind et al., 2007). Although Clara cells are unique to the lung, this specific protein is measurable in circulation by diffusing into plasma across the LBAB (Lakind et al., 2007; Hermans and Bernard 1999).

We here designed a panel study of healthy nonsmokers carried out in Shanghai to evaluate the short-term effect of personal $\mathrm{PM}_{2.5}$ exposure on lung function and serum $\mathrm{CC} 16$. We also examined whether the LBAB integrity, here assessed by serum CC16, plays a role in the decreased lung function caused by $\mathrm{PM}_{2.5}$.

\section{Material and Methods}

\subsection{Study population and design}

Data were collected from 36 healthy college students from Fudan University and East China University of Science and Technology, Shanghai, China. The specific information about the study design has been reported previously (Wang et al., 2016). 
This longitudinal panel study involved repeated measurements at 4 time points (Wang et al., 2016). Each measurement entailed 72 hours of continuous monitoring. To expand the temporal variations in exposure to $\mathrm{PM}_{2.5}$, we scheduled follow-ups in various days of the week in each round, with about twoweek interval between each round. Fieldwork was carried out between December 17, 2014 and July 11, 2015.

All participants were nonsmokers and all of them provided written informed consent before enrollment. The Institutional Review Board of the School of Public Health, Fudan University approved the study protocol (IRB\#2014-TYSQ-09-1).

\subsection{Individual $P M_{2.5}$ exposure monitoring}

We used MicroPEM monitors (v3.2 MicroPEM, RTI, USA) to record the realtime $\mathrm{PM}_{2.5}$ concentrations and $\mathrm{HOBO}$ data loggers (Onset Computer Corporation, Pocasset, Massachusetts) to simultaneously monitor personal exposure temperature and relative humidity. Exposure data were recorded once every half hour.

The participants were required to come to Fudan University on Day 1 between 10:00 am and 11:00 am to wear a vest with MicroPEM and HOBO and start their monitoring devices. On Day 4, between 10:00 am and 11:00 am, the subjects were required to turn in their monitoring devices. All participants were asked to wear the vests continuously throughout the 72 hours, except when sleeping, taking a shower or engaging in strenuous sports activities, during which times, vest was to be hung at the level of the breathing zone near the site of the activity. 


\subsection{Pulmonary function measurement}

On Day 4 when the subjects turned in their vests, they were required to carry out a series of physiological and biological measurements that included spirometry and phlebotomy. Spirometry was performed using a Fleisch pneumotachograph type spirometer (KoKo ${ }^{\mathrm{TM}}$, nSpire Longmont Co, USA). Before the health examination, the spirometer was calibrated by a Calibration Pump (SN: 95290967, Calibration Syringe 3.0 L, CareFusion, Germany)

The same trained lung function technician performed the testing to reduce the surveyor error. Lung function was measured three to eight times at intervals of 3 minutes, and the error of every two measurements of each parameter was required to be within $5 \%$ before being recorded as a valid data point. Only the spirograms meeting international standards were accepted at the time of testing (Renzetti 1979).

The lung function parameters examined in this study were the conventional spirometric indices used to detect impairment: $F E V_{1}$, which measures the maximum volume that can be exhaled within $1 \mathrm{sec}$; FVC, which measures the total volume exhaled after a maximum inspiration; $\mathrm{FEV}_{1} / \mathrm{FVC}$; peak expiratory flow (PEF), which tests the airflow through the bronchi and thus the degree of obstruction in the airways; forced expiratory flow at $25 \%-75 \%$ of the pulmonary volume $\left(\mathrm{FEF}_{25-75}\right)$, which is also used to reflect the obstruction in small airways.

\subsection{CC16 detection}

We collected blood samples from participants between 10:00 and11:00 am on day 4 of each round. Blood samples were incubated at $37^{\circ} \mathrm{C}$ for $10 \mathrm{~min}$, 
centrifuged at $4000 \mathrm{rpm}$ for $10 \mathrm{~min}$, transferred to $1 \mathrm{ml}$ microtubes (Nunc, Naperville, IL, USA), and transferred to $-80{ }^{\circ} \mathrm{C}$ for storage. All of these procedures were completed within 1 hour after blood collection to minimize in vitro changes in CC16 levels.

We measured CC16 using enzyme-linked immunosorbent assays according to the manufacturer's instructions (R\&D, Human Uteroglobin Quantikine ELISA Kit, USA).

\subsection{Statistical analysis}

Because there were repeated measures for all participants, we used linear

mixed effect (LME) models to estimate the effect of $\mathrm{PM}_{2.5}$ on lung function and CC16. This linear mixed model, by including a random effect for subject, allows each subject to serve as his/her control over time and also accounts for correlations among multiple repeated measurements collected per person (Verbeke and Molenberghs 2009). Lung function and CC16 level were natural log-transformed to better approximate a normal distribution among residuals.

Personal exposure levels $\left(\mathrm{PM}_{2.5}\right.$, temperature and relative humidity) were averaged over predetermined time intervals, including disjoint periods preceding the time of the health examination, that is, single lag intervals of $0-6$ hour $(\mathrm{h}), 7$ $24 \mathrm{~h}, 25-48 \mathrm{~h}$ and 49-72 h. The integrated time-specific $\mathrm{PM}_{2.5}$ was incorporated in the model as a fixed-effect predictor. Other potential fixed-effect covariates included age, sex, body mass index (BMI), temperature, relative humidity, day of the week and experimental plate for CC16. We did not adjust for time trends for 
possible seasonal effects because all four visits for each subject were completed within two months (Wang et al., 2016).

We conducted mediation analyses to evaluate and quantify the contribution of circulating $\mathrm{CC} 16$ levels in the process of lung function injury induced by $\mathrm{PM}_{2.5}$. This approach decomposed the total observed effect of $\mathrm{PM}_{2.5}$ exposure on lung function into a direct observed effect and a causal mediation effect that goes through CC16 (Peng et al., 2016).

All analyses were conducted with R software (version 2.15.3, R development Core Team) using the "Ime4" package for LEM models and "mediation" package for mediation analysis. Statistical tests were two-sided, with $\mathrm{P} \leq 0.05$ considered statistically significant.

\section{Results}

\subsection{Data description}

A total of 14 males and 22 females, with a mean average age of 24 years, were enrolled in this study. BMI varied from 16.2 to $31.3 \mathrm{~kg} / \mathrm{m}^{2}$, with an average of $21.2 \mathrm{~kg} / \mathrm{m}^{2}$. As one participant missed the last visit, we obtained data for 143 repetitions of the subjects.

Table 1 provides the descriptive statistics of personal exposure to $\mathrm{PM}_{2.5}$, temperature and relative humidity. The average exposure to $\mathrm{PM}_{2.5}$ ranged from 40 to $52 \mu \mathrm{g} / \mathrm{m}^{3}$ across the lag periods. There was substantial intra- and interindividual variation in $\mathrm{PM}_{2.5}$ exposure levels, with the coefficients of variation (CV) ranging from 0.68 to 1.15 (data not shown). The personal data on temperature 
and humidity also differed within and between the subjects, with the CV ranging from 0.19 to 0.24 for temperature and from 0.18 to 0.23 for humidity, respectively (data not shown). Table 2 shows the descriptive statistics for lung function and CC16. Serum CC16 levels ranged from $12.59 \mathrm{ng} / \mathrm{mL}$ to $51.55 \mathrm{ng} / \mathrm{mL}$, with a mean of $23.90 \mathrm{ng} / \mathrm{mL}$.

(Please insert Table 1 here)

(Please insert Table 2 here)

There were negative associations between $\mathrm{PM}_{2.5}$ levels and lung function of

\subsection{Individual $P M_{2.5}$-lung function relationship} $\mathrm{FEV}_{1}, \mathrm{FVC}, \mathrm{FEV}_{1} / \mathrm{FVC}$ and PEF, usually occurring within the first $24 \mathrm{~h}$ after exposure (Figure 1). For example, at lag 0-6 h, an interquartile range (IQR 25.9 $\mu \mathrm{g} / \mathrm{m}^{3}$ ) increase in personal exposure to $\mathrm{PM}_{2.5}$ was associated with decreases of 1.11\% (95\%Cl: $0.50 \%, 1.71 \%)$ in $\mathrm{FEV}_{1}, 1.00 \%(95 \% \mathrm{Cl}: 0.29 \%, 1.73 \%)$ in $\mathrm{FVC}$, 1.33\% (95\%Cl: $0.65 \%, 2.01 \%)$ in $\mathrm{FEV}_{1} / \mathrm{FVC}$ and $1.02 \%$ (95\%Cl: $\left.0.12 \%, 1.92 \%\right)$ in PEF. However, there were no significant short-term associations between $\mathrm{PM}_{2.5}$ levels and $\mathrm{FEF}_{25-75}$ at all lag times.

(Please insert Figure 1 here)

\subsection{Individual $P M_{2.5}-C C 16$ relationship}

$\mathrm{PM}_{2.5}$ was positively associated with $\mathrm{CC} 16$ within the first $24 \mathrm{~h}$ (Figure 2). For example, an IQR increase in personal exposure to $\mathrm{PM}_{2.5}$ was associated with increases of $4.14 \%(95 \% \mathrm{Cl}: 0.86 \%, 7.41 \%)$ and $4.10 \%(95 \% \mathrm{Cl}: 0.93 \%, 7.27 \%)$ at lags of $0-6 \mathrm{~h}$ and $7-24 \mathrm{~h}$, respectively.

(Please insert Figure 2 here) 


\subsection{Mediation analysis}

We estimated the mediated effect of serum CC16 using lags of $0-6 \mathrm{~h}$ and 7 $24 \mathrm{~h}$, respectively. As shown in Table 3, we found a significant mediation in the process of "PM $\mathrm{P}_{2.5} \rightarrow \mathrm{CC} 16 \rightarrow \mathrm{FEV}_{1} / \mathrm{FVC}$ ", that was, the pulmonary epithelial hyperpermeability mediated $34.4 \%$ of the association between $\mathrm{PM}_{2.5}$ exposure and $\mathrm{FEV}_{1} / \mathrm{FVC}$ at lag 7-24 $\mathrm{h}(\mathrm{P}=0.05)$. The mediations of other parameters of lung function were positive but not statistically significant (Proportion $=3.9 \% \sim 40.0 \%$, $\mathrm{P}=0.17 \sim 0.86)$.

(Please insert Table 3 here)

\section{Discussion}

In the present panel study of young, healthy adults with personal $\mathrm{PM}_{2.5}$ monitoring, we found that acute exposure to $\mathrm{PM}_{2.5}$ was associated with decrements in lung function parameters. The effect of $\mathrm{PM}_{2.5}$ on FVC and PEF occurred within the first $6 \mathrm{~h}$ and the effects on $\mathrm{FEV}_{1}$ and $F E V_{1} / F V C$ remained for the first $24 \mathrm{~h}$. We did not find a significant association between $\mathrm{PM}_{2.5}$ and $\mathrm{FEF}_{25}$ 75 .

To the best of our knowledge, this study is the first panel study to report the effects of individual measurements of $\mathrm{PM}_{2.5}$ exposure on lung function among a young healthy adult population. The estimated health effects of $\mathrm{PM}_{2.5}$ exposure on lung function in our analysis were comparable to previous studies. For example, in a one-day hike in Boston, USA, Korrick et al. found that FVC declined for $0.4 \%(95 \% \mathrm{Cl}: 0.2 \%, 0.6 \%)$ across the IQR $\left(9 \mu \mathrm{g} / \mathrm{m}^{3}\right)$ for $\mathrm{PM}_{2.5}$ among adult hikers (Korrick et al., 1998). Schindler et al. also found that an IQR 

and $0.35 \%(95 \% \mathrm{Cl}: 0.04 \%, 0.66 \%)$ decreases in $\mathrm{FEV}_{1}$ and $\mathrm{FVC}$, respectively, in a Canadian Health Measures Survey (Korrick et al., 1998). Moshammer et al. studied a panel of schoolchildren in Austria and reported a $0.41 \%(P=0.027)$ decrease in PEF for an increase of $10 \mu \mathrm{g} / \mathrm{m}^{3}$ in $\mathrm{PM}_{2.5}$ after an 8 hours exposure (Moshammer et al., 2006). The only previous panel study with healthy, nonsmoking college students carried out in Wuhan University, China, showed that a $10 \mu \mathrm{g} / \mathrm{m}^{3}$ increase of outdoor $\mathrm{PM}_{2.5}$ was associated with $1.54 \mathrm{~L} / \mathrm{min}(95 \% \mathrm{Cl}$ : 0.04, 3.03) decreases in evening PEF on the day after exposure (Zhang et al., 2015). However, another panel study conducted in Beijing, China, did not find a 250 significant association between $\mathrm{PM}_{2.5}$ and $\mathrm{FEV}_{1}$ or $\mathrm{FVC}$ among truck drivers permeability (Broeckaert et al., 2000a; Hermans et al., 1999), is positively (Baccarelli et al., 2014).

Our study found that serum CC16, a biomarker of LBAB integrity and associated with acute exposure to $\mathrm{PM}_{2.5}$ among young healthy adults, occurring $6 \mathrm{~h}$ after exposure and lasting for $24 \mathrm{~h}$, which was consistent with previous epidemiological studies (Bernard et al., 1997; Broeckaert et al., 2000a; Burgess et al., 2001). For instance, in Belgium, Bernard et al. conducted an intervention experiment among firefighter and found that the serum CC16 levels elevated by $320 \%$ on average after $0.5 \sim 1 \mathrm{~h}$ exposure to the fire, compared to normal levels. ${ }^{28}$ Provost et al. found an increase of $0.21 \mu \mathrm{g} / \mathrm{L}(95 \% \mathrm{Cl}: 0.10,0.32)$ in circulating CC16 with each $5 \mu \mathrm{g} / \mathrm{m}^{3}$ elevation in $\mathrm{PM}_{10}$ after 1 day of exposure and this upward trend persisted for 1 week among Belgian adolescents (Provost et al., 
2014). Another two studies found urine CC16 also increased after exposure to $\mathrm{PM}_{2.5}$, with a time lag beginning slightly later (24 h) than that observed in blood (Jacquemin et al., 2009; Timonen et al., 2004). However, in a traffic-related 266 health study, Zuurbier et al. did not find the associations between $\mathrm{PM}_{2.5}$ exposure and changes in serum $\mathrm{CC} 16$ after $2 \mathrm{~h}$ commute during the morning rush hour 268 (Zuurbier et al., 2011), which was in line with another traffic-related study assessing the association between $\mathrm{PM}_{2.5}$ and pulmonary function, including serum CC16 (Zhao et al., 2015).

It has been suggested that changes in serum CC16 levels may stem from three basic mechanisms: i) decreased secretion in the respiratory tract; ii) increased leakage through the LBAB; or iii) a reduction of renal clearance (Broeckaert et al., 2000b). However, acute increased CC16 levels in circulation induced by air pollutants, including smoking (Bernard et al., 1997) and ozone (Broeckaert et al., 2000a), could be regarded as a peripheral indicator for reflecting the leakage of the LBAB despite a decreased production of $\mathrm{CC} 16$ from damaged Clara cells (Brauner et al., 2009; Hermans et al., 1999). Although increased circulating CC16 across the LBAB could be used as a surrogate for indicating epithelium impairment (Broeckaert et al., 2000a; Broeckaert and Bernard 2000), the relationship between $\mathrm{PM}_{2.5}$, the integrity of lung epithelium and early lung function abnormalities has not been well characterized. In this study, we found a significant mediating effect (proportion=34.4\%, $\mathrm{P}=0.05$ ) of CC16 serum levels in the association between $\mathrm{PM}_{2.5}$ and $F E V_{1} / F V C$ at lag 7-24 $\mathrm{h}$. That is to say, $34.4 \%$ of the $\mathrm{PM}_{2.5}$-induced lung function decline might be 
explained by the hyper-permeability of the LBAB. Our findings suggest a potential involvement of lung epithelium integrity in the acute effects of $\mathrm{PM}_{2.5}$ on impaired lung function.

The current study has several strengths. First, compared to previous panel studies, which relied on outdoor fixed air quality monitors, our study based on real-time personal sampling can estimate exposure levels more accurately. Second, the LME models allowed each subject to serve as his/her own control and accounted for correlations among repeated measurements within the subject (Verbeke and Molenberghs 2009). Third, because only healthy, young and nonwhich might have confounded our findings (Blomberg et al., 2003).

\section{Conclusion}

This study on healthy young adults suggested that acute exposure to $\mathrm{PM}_{2.5}$ was significantly associated with lung function impairment and increase in circulating CC16. Our findings also highlighted a possible involvement of the LBAB in the effects of acute injury on lung function by $\mathrm{PM}_{2.5}$. Future work is 
needed to elucidate the role of $\angle B A B$ in the health effects of $\mathrm{PM}_{2.5}$ on lung function in a more controlled experimental setting or in animal models.

Funding information: This work was funded by the Public Welfare Research Program of National Health and Family Planning Commission of China (201502003), China Medical Board Collaborating Program (13-152) and the Shanghai 3-Year Public Health Action Plan (GWTD2015S04).

\section{Acknowledgements}

The authors appreciated the contribution of all subjects in this study. We thanked the editorial assistance of the NIH Fellows Editorial Board in language improvement. 
321

322

323

324

325

326

327

328

329

330

331

332

333

334

335

336

337

338

339

340

341

342

\section{References}

Baccarelli, A.A., Zheng, Y., Zhang, X., Chang, D., Liu, L., Wolf, K.R., Zhang, Z., McCracken, J.P., Diaz, A., Bertazzi, P.A., Schwartz, J., Wang, S., Kang, C.M., Koutrakis, P., Hou, L., 2014. Air pollution exposure and lung function in highly exposed subjects in Beijing, China: a repeated-measure study. Part Fibre Toxicol 11,51 .

Bernard, A., Hermans, C., Van Houte, G., 1997. Transient increase of serum Clara cell protein (CC16) after exposure to smoke. Occup Environ Med 54, 63-65.

Blomberg, A., Mudway, I., Svensson, M., Hagenbjork-Gustafsson, A., Thomasson, L., Helleday, R., Dumont, X., Forsberg, B., Nordberg, G., Bernard, A., 2003. Clara cell protein as a biomarker for ozone-induced lung injury in humans. Eur Respir J 22, 883-888.

Brauner, E.V., Mortensen, J., Moller, P., Bernard, A., Vinzents, P., Wahlin, P., Glasius, M., Loft, S., 2009. Effects of ambient air particulate exposure on blood-gas barrier permeability and lung function. Inhal Toxicol 21, 38-47.

Broeckaert, F., Arsalane, K., Hermans, C., Bergamaschi, E., Brustolin, A., Mutti, A., Bernard, A., 1999. Lung epithelial damage at low concentrations of ambient ozone. Lancet 353, 900-901.

Broeckaert, F., Arsalane, K., Hermans, C., Bergamaschi, E., Brustolin, A., Mutti, A., Bernard, A., 2000a. Serum clara cell protein: a sensitive biomarker of increased lung epithelium permeability caused by ambient ozone. Environ Health Perspect $108,533-537$. 
343 Broeckaert, F., Bernard, A., 2000. Clara cell secretory protein (CC16): characteristics and perspectives as lung peripheral biomarker. Clin Exp Allergy 30, 469-475.

Broeckaert, F., Clippe, A., Knoops, B., Hermans, C., Bernard, A., 2000b. Clara cell secretory protein (CC16): features as a peripheral lung biomarker. Ann N Y Acad Sci 923, 68-77.

Burgess, J.L., Nanson, C.J., Bolstad-Johnson, D.M., Gerkin, R., Hysong, T.A., Lantz, R.C., Sherrill, D.L., Crutchfield, C.D., Quan, S.F., Bernard, A.M., Witten, M.L., 2001. Adverse respiratory effects following overhaul in firefighters. J Occup Environ Med 43, 467-473.

Fuertes, E., Bracher, J., Flexeder, C., Markevych, I., Klumper, C., Hoffmann, B., Kramer, U., von Berg, A., Bauer, C.P., Koletzko, S., Berdel, D., Heinrich, J., Schulz, H., 2015. Long-term air pollution exposure and lung function in 15 year-old adolescents living in an urban and rural area in Germany: The GINIplus and LISAplus cohorts. Int J Hyg Environ Health 218, 656-665.

Gauderman, W.J., Avol, E., Gilliland, F., Vora, H., Thomas, D., Berhane, K., McConnell, R., Kuenzli, N., Lurmann, F., Rappaport, E., Margolis, H., Bates, D., Peters, J., 2004. The effect of air pollution on lung development from 10 to 18 years of age. $\mathrm{N}$ Engl $\mathrm{J}$ Med 351, 1057-1067.

Verbeke G, Molenberghs G. Linear mixed models for longitudinal data. New York: Springer Science \& Business Media; 2009.

Hermans, C., Bernard, A., 1999. Lung epithelium-specific proteins: characteristics and potential applications as markers. Am J Respir Crit Care Med 159, 646-678. 
Hermans, C., Knoops, B., Wiedig, M., Arsalane, K., Toubeau, G., Falmagne, P., Bernard, A., 1999. Clara cell protein as a marker of Clara cell damage and bronchoalveolar blood barrier permeability. Eur Respir J 13, 1014-1021.

Jacquemin, B., Lanki, T., Yli-Tuomi, T., Vallius, M., Hoek, G., Heinrich, J., Timonen, K., Pekkanen, J., 2009. Source category-specific PM2.5 and urinary levels of Clara cell protein CC16. The ULTRA study. Inhal Toxicol 21, 1068-1076.

Kariisa, M., Foraker, R., Pennell, M., Buckley, T., Diaz, P., Criner, G.J., Wilkins, J.R., 3rd, 2015. Short- and long-term effects of ambient ozone and fine particulate matter on the respiratory health of chronic obstructive pulmonary disease subjects. Arch Environ Occup Health 70, 56-62.

Korrick, S.A., Neas, L.M., Dockery, D.W., Gold, D.R., Allen, G.A., Hill, L.B., Kimball, K.D., Rosner, B.A., Speizer, F.E., 1998. Effects of ozone and other pollutants on the pulmonary function of adult hikers. Environ Health Perspect 106, 93-99.

Lakind, J.S., Holgate, S.T., Ownby, D.R., Mansur, A.H., Helms, P.J., Pyatt, D., Hays, S.M., 2007. A critical review of the use of Clara cell secretory protein (CC16) as a biomarker of acute or chronic pulmonary effects. Biomarkers 12, 445-467.

Lee, J.T., Son, J.Y., Cho, Y.S., 2007. The adverse effects of fine particle air pollution on respiratory function in the elderly. Sci Total Environ 385, 28-36.

Moshammer, H., Hutter, H.P., Hauck, H., Neuberger, M., 2006. Low levels of air pollution induce changes of lung function in a panel of schoolchildren. Eur Respir $\mathrm{J}$ $27,1138-1143$.

Mu, L., Deng, F., Tian, L., Li, Y., Swanson, M., Ying, J., Browne, R.W., RittenhouseOlson, K., Zhang, J.J., Zhang, Z.F., Bonner, M.R., 2014. Peak expiratory flow, 
breath rate and blood pressure in adults with changes in particulate matter air pollution during the Beijing Olympics: a panel study. Environ Res 133, 4-11.

Ni, Y., Wu, S., Ji, W., Chen, Y., Zhao, B., Shi, S., Tu, X., Li, H., Pan, L., Deng, F., Guo, X., 2016. The exposure metric choices have significant impact on the association between short-term exposure to outdoor particulate matter and changes in lung function: Findings from a panel study in chronic obstructive pulmonary disease patients. Sci Total Environ 542, 264-270.

Paulin, L., Hansel, N., 2016. Particulate air pollution and impaired lung function. F1000Res 5.

Peng, C., Bind, M.C., Colicino, E., Kloog, I., Byun, H.M., Cantone, L., Trevisi, L., Zhong, J., Brennan, K., Dereix, A.E., Vokonas, P.S., Coull, B.A., Schwartz, J.D., Baccarelli, A.A., 2016. Particulate Air Pollution and Fasting Blood Glucose in Non-Diabetic Individuals: Associations and Epigenetic Mediation in the Normative Aging Study, 2000-2011. Environ Health Perspect.

Provost, E.B., Chaumont, A., Kicinski, M., Cox, B., Fierens, F., Bernard, A., Nawrot, T.S., 2014. Serum levels of club cell secretory protein (Clara) and short- and longterm exposure to particulate air pollution in adolescents. Environ Int 68, 66-70.

Renzetti, A.D., Jr., 1979. Standardization of spirometry. Am Rev Respir Dis 119, 693694.

Rice, M.B., Rifas-Shiman, S.L., Litonjua, A.A., Oken, E., Gillman, M.W., Kloog, I., Luttmann-Gibson, H., Zanobetti, A., Coull, B.A., Schwartz, J., Koutrakis, P., Mittleman, M.A., Gold, D.R., 2016. Lifetime Exposure to Ambient Pollution and Lung Function in Children. Am J Respir Crit Care Med 193, 881-888. 
411 Schindler, C., Kunzli, N., Bongard, J.P., Leuenberger, P., Karrer, W., Rapp, R., Monn, 412 C., Ackermann-Liebrich, U., 2001. Short-term variation in air pollution and in Lung Diseases in Adults (SAPALDIA). Am J Respir Crit Care Med 163, 356-361.

Timonen, K.L., Hoek, G., Heinrich, J., Bernard, A., Brunekreef, B., de Hartog, J., Hameri, K., Ibald-Mulli, A., Mirme, A., Peters, A., Tiittanen, P., Kreyling, W.G., Pekkanen, J., 2004. Daily variation in fine and ultrafine particulate air pollution and urinary concentrations of lung Clara cell protein CC16. Occup Environ Med 61, 908-914. Trenga, C.A., Sullivan, J.H., Schildcrout, J.S., Shepherd, K.P., Shapiro, G.G., Liu, L.J., Kaufman, J.D., Koenig, J.Q., 2006. Effect of particulate air pollution on lung function in adult and pediatric subjects in a Seattle panel study. Chest 129, 1614-1622.

Wang, C., Chen, R., Cai, J., Shi, J., Yang, C., Tse, L.A., Li, H., Lin, Z., Meng, X., Liu, C., Niu, Y., Xia, Y., Zhao, Z., Kan, H., 2016. Personal exposure to fine particulate matter and blood pressure: A role of angiotensin converting enzyme and its DNA methylation. Environ Int 94, 661-666.

Winkelmann A., Noack T., 2010. The Clara cell: a "Third Reich eponym"? Eur Respir J $36,722-727$.

Zhang, Y., He, M., Wu, S., Zhu, Y., Wang, S., Shima, M., Tamura, K., Ma, L., 2015. Short-Term Effects of Fine Particulate Matter and Temperature on Lung Function among Healthy College Students in Wuhan, China. Int J Environ Res Public Health 12, 7777-7793. 
432 Zhao, J., Bo, L., Gong, C., Cheng, P., Kan, H., Xie, Y., Song, W., 2015. Preliminary

433 study to explore gene-PM2.5 interactive effects on respiratory system in traffic

434 policemen. Int J Occup Med Environ Health 28, 971-983.

435 Zuurbier, M., Hoek, G., Oldenwening, M., Meliefste, K., Krop, E., van den Hazel, P.,

436 Brunekreef, B., 2011. In-traffic air pollution exposure and CC16, blood coagulation,

437 and inflammation markers in healthy adults. Environ Health Perspect 119, 1384-

438 1389. 
439 Table 1. The descriptive statistics on personal $\mathrm{PM}_{2.5}$, temperature and relative

440 humidity at different averaging periods preceding the health outcomes measurements.

\begin{tabular}{|c|c|c|c|c|c|c|c|}
\hline Variables & Lag & Mean & SD & Min & Median & $\operatorname{Max}$ & IQR \\
\hline \multirow[t]{5}{*}{$\mathrm{PM}_{2.5}\left(\mu \mathrm{g} / \mathrm{m}^{3}\right)$} & $0-6 \mathrm{~h}$ & 39.69 & 45.89 & 1.68 & 26.81 & 226.40 & 25.88 \\
\hline & $7-24 \mathrm{~h}$ & 42.48 & 41.00 & 7.83 & 28.74 & 191.50 & 32.93 \\
\hline & $0-24 \mathrm{~h}$ & 42.00 & 41.18 & 7.03 & 28.39 & 200.30 & 26.78 \\
\hline & $25-48 \mathrm{~h}$ & 52.28 & 43.28 & 8.92 & 36.42 & 197.20 & 48.10 \\
\hline & $49-72 \mathrm{~h}$ & 48.16 & 32.53 & 6.10 & 39.78 & 249.10 & 39.21 \\
\hline \multirow[t]{5}{*}{ Temperature $\left({ }^{\circ} \mathrm{C}\right)$} & $0-6 \mathrm{~h}$ & 21.85 & 5.16 & 9.88 & 24.36 & 28.57 & 7.79 \\
\hline & $7-24 \mathrm{~h}$ & 22.64 & 4.50 & 9.97 & 24.69 & 28.54 & 6.25 \\
\hline & $0-24 \mathrm{~h}$ & 22.44 & 4.64 & 10.24 & 24.60 & 28.54 & 6.67 \\
\hline & $25-48 \mathrm{~h}$ & 22.46 & 4.43 & 10.76 & 24.03 & 29.01 & 6.06 \\
\hline & $49-72 \mathrm{~h}$ & 22.38 & 4.33 & 10.43 & 23.29 & 30.85 & 6.78 \\
\hline \multirow[t]{5}{*}{ Relative humidity (\%) } & $0-6 \mathrm{~h}$ & 60.36 & 10.83 & 36.04 & 60.78 & 84.99 & 15.37 \\
\hline & $7-24 \mathrm{~h}$ & 53.98 & 11.77 & 27.54 & 52.20 & 74.78 & 18.93 \\
\hline & $0-24 \mathrm{~h}$ & 55.57 & 11.25 & 31.04 & 54.97 & 75.96 & 17.48 \\
\hline & $25-48 \mathrm{~h}$ & 55.88 & 11.11 & 25.16 & 56.74 & 78.54 & 17.70 \\
\hline & $49-72 \mathrm{~h}$ & 55.33 & 12.63 & 22.71 & 54.84 & 81.56 & 19.64 \\
\hline
\end{tabular}


443 Table 2. Summary statistics of lung function and CC16.

\begin{tabular}{llllll}
\hline Variables & Mean & SD & Min & Median Max & IQR \\
\hline
\end{tabular}

Lung function

$\begin{array}{lllllll}\mathrm{FEV}_{1}\left(\mathrm{~L}_{1}^{\mathrm{st}} \mathrm{sec}\right) & 3.22 & 0.51 & 2.20 & 3.26 & 4.33 & 0.78 \\ \mathrm{FVC}(\mathrm{L}) & 3.76 & 0.67 & 2.23 & 3.68 & 5.51 & 0.95 \\ \mathrm{FEV}_{1} / \mathrm{FVC} & 86.37 & 6.97 & 66.73 & 86.43 & 99.63 & 9.72 \\ \mathrm{PEF}(\mathrm{L} / \mathrm{s}) & 7.10 & 1.65 & 4.20 & 6.62 & 11.1 & 2.42 \\ \mathrm{FEF}_{25-75}(\mathrm{~L} / \mathrm{s}) & 3.47 & 0.84 & 1.93 & 3.41 & 5.90 & 1.17 \\ \mathrm{CC} 16(\mathrm{ng} / \mathrm{mL}) & 23.90 & 6.83 & 12.59 & 22.71 & 51.55 & 7.63\end{array}$

444 Abbreviations: $\mathrm{FEV}_{1}$, forced expiratory volume in $1 \mathrm{sec}$; $\mathrm{FVC}$, forced vital capacity;

445 PEF, peak expiratory flow; $\mathrm{FEF}_{25-75}$, forced expiratory flow at $25 \%-75 \%$ of the 446 pulmonary volume; CC16, Clara cell protein. 
447 Table 3. The proportion of $\mathrm{PM}_{2.5}$ on lung function that mediated by $\mathrm{CC} 16$.

\begin{tabular}{|c|c|c|}
\hline Lung function & $\begin{array}{l}\text { Lag 0-6 h } \\
\text { Proportion (\%) (P) }\end{array}$ & $\begin{array}{l}\text { Lag 7-24 h } \\
\text { Proportion (\%) (P) }\end{array}$ \\
\hline $\mathrm{FEV}_{1}\left(\mathrm{~L} 1^{\mathrm{st}} \mathrm{sec}\right)$ & $4.91(0.63)$ & $3.86(0.54)$ \\
\hline $\mathrm{FVC}(\mathrm{L})$ & $29.7(0.33)$ & $5.04(0.69)$ \\
\hline $\mathrm{FEV}_{1} / \mathrm{FVC}$ & $40.02(0.17)$ & $34.4(0.05)$ \\
\hline PEF (L) & $9.5(0.54)$ & $18.4(0.38)$ \\
\hline $\mathrm{FEF}_{25-75}(\mathrm{~L} / \mathrm{s})$ & $9.3(0.47)$ & $14.7(0.86)$ \\
\hline
\end{tabular}




\section{FIGURE LEGENDS:}

452 FIGURE 1. Changes in a) $F E V_{1}$, b) FVC, c) FEV $1 / F V C$, d) PEF and e) $F F_{25-75}$ 453 associated with an interquartile range increase of personal $\mathrm{PM}_{2.5}$ levels using different 454 lag structures. The $\mathrm{X}$-axis refers to different time windows; the $\mathrm{Y}$-axis refers to the 455 corresponding changes (mean and 95\% confidence intervals).

456 Abbreviation: $\mathrm{FEV}_{1}$, forced expiratory volume in $1 \mathrm{sec}$; FVC, forced vital capacity; PEF, 457 peak expiratory flow; $\mathrm{FEF}_{25-75}$, forced expiratory flow at $25 \%-75 \%$ of the pulmonary 458 volume.

459 FIGURE 2. Changes in $\mathrm{CC} 16$ associated with an interquartile range increase of 460 personal $\mathrm{PM}_{2.5}$ levels using different lag structures. The $\mathrm{X}$-axis refers to different time 461 window; the $\mathrm{Y}$-axis refers to the corresponding changes (mean and 95\% confidence 462 intervals).

463 Abbreviation: CC16, Clara cell protein. 

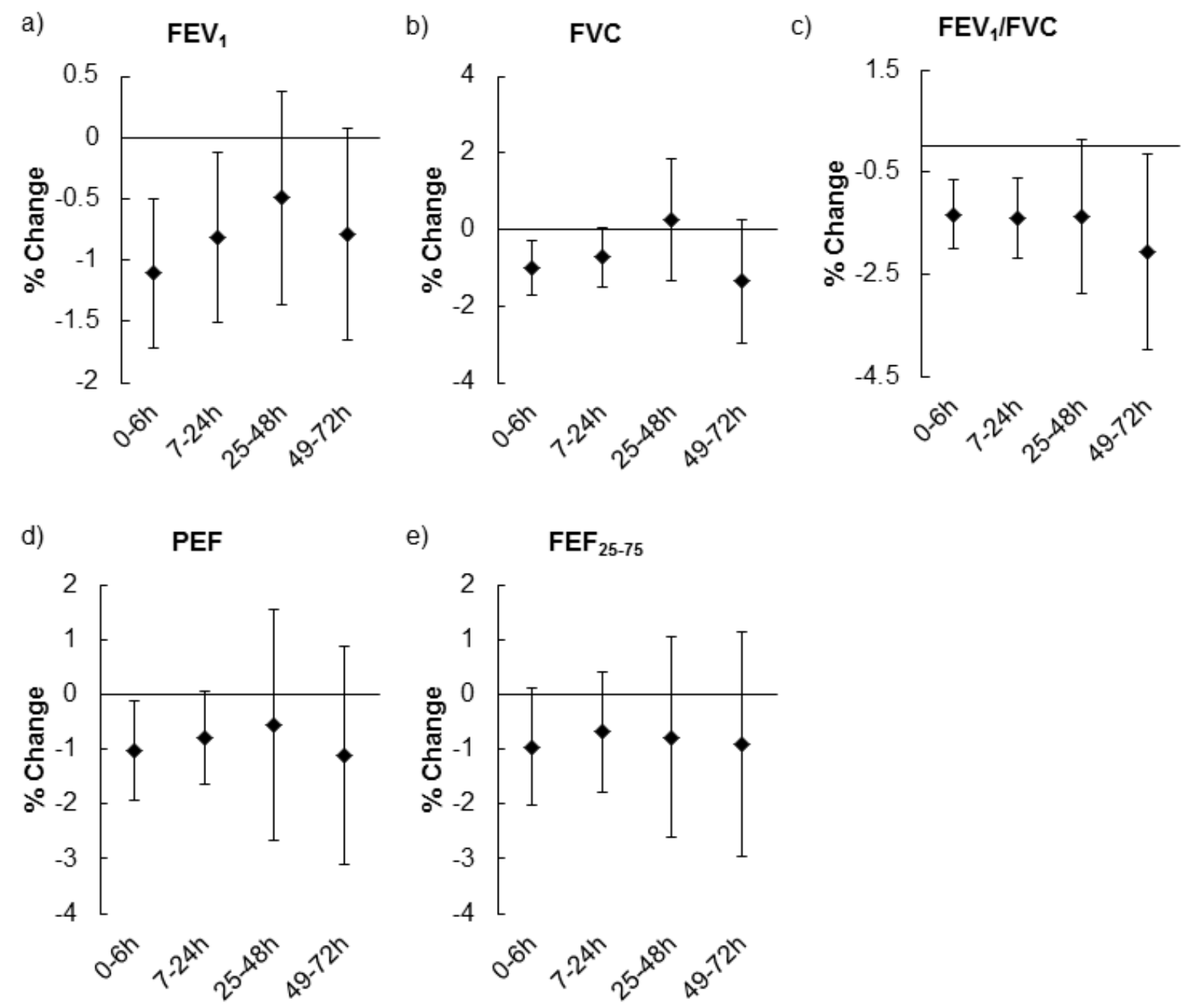

464

465

466 


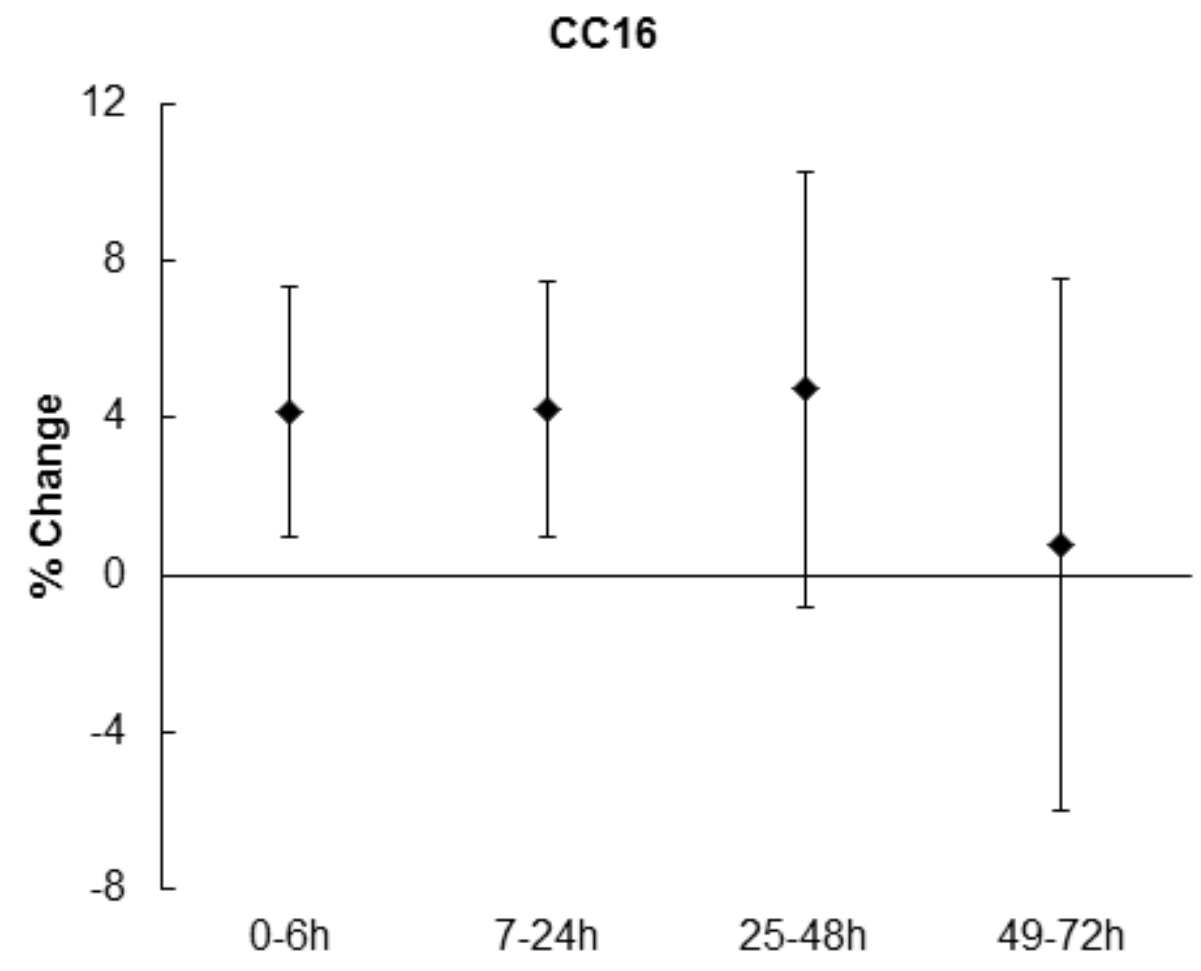


FEV $_{1}$ /FVC

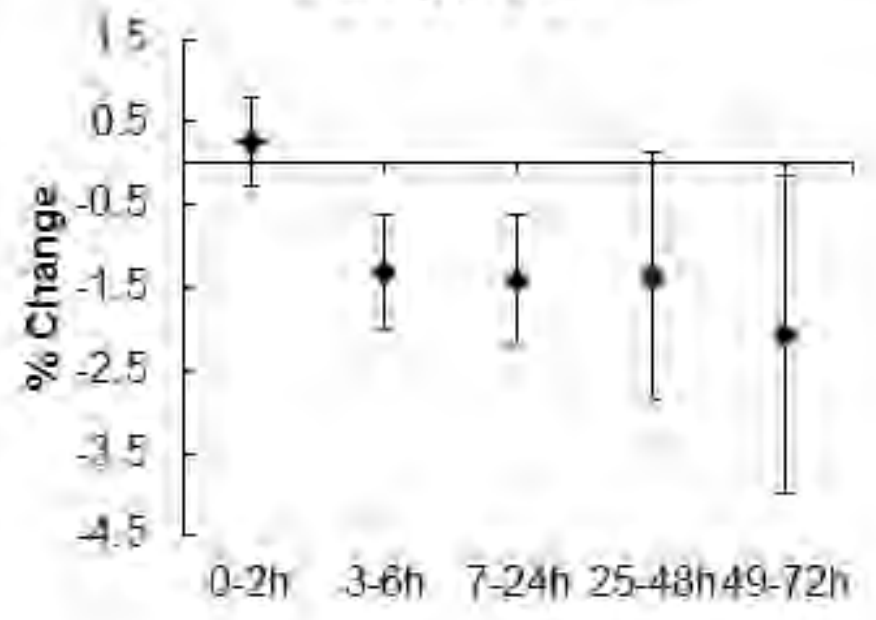

CC16

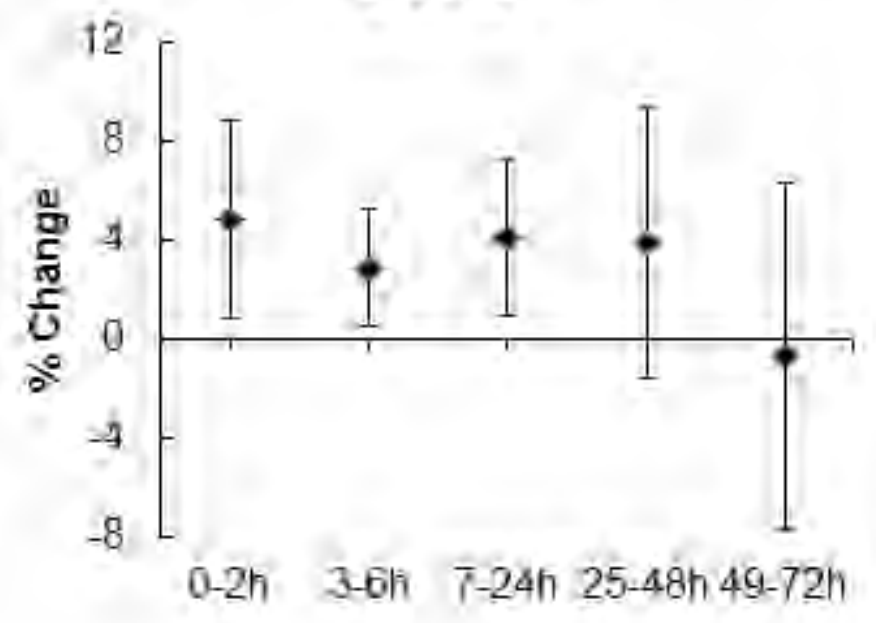

\section{CC16 ( mediate 34.4\%)}

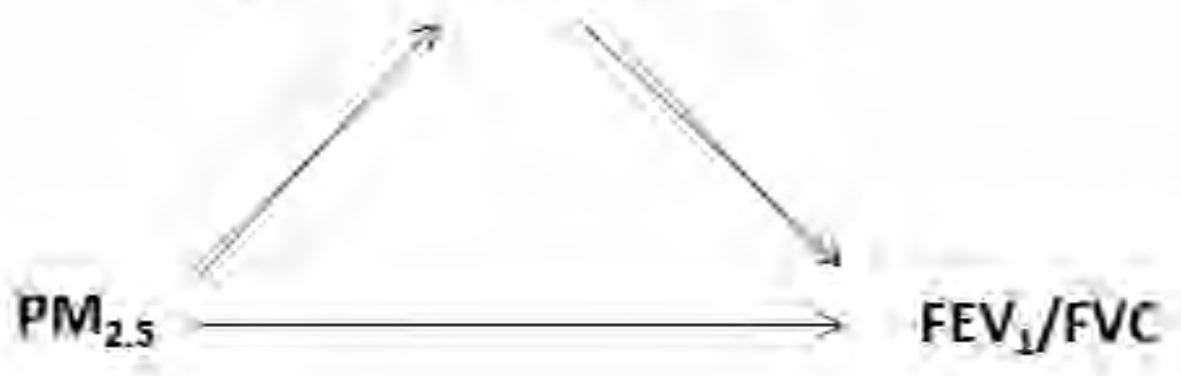

